\title{
RESTAURACIÓN ECOLÓGICA Y PAISAJISTICA DEL ARROYO DE LOS QUIÑONES. SAN SEBASTIÁN DE LOS REYES, MADRID
}

\author{
(ECOLOGICAL AND LANDSCAPE RESTORATION OF THE ARROYO DE LOS \\ QUIÑONES. SAN SEBASTIÁN DE LOS REYES, MADRID) \\ Pedro Peinado Albendea* y Juan Pablo Villafañe*, Biólogos \\ Proyecto realizado para el Ayuntamiento de San Sebastián de los Reyes, Madrid
}

ESPAÑA

Fecha de recepción: 6-X-95

$113-42$

\section{RESUMEN}

La restauración del Arroyo de los Quiñones (San Sebastián de los Reyes, Madrid) plantea como problema resolver sus principales fuentes de degradación. Éstas son los vertidos de aguas residuales, un vertedero de residuos sólidos urbanos ubicado en el cauce, y la intensiva extracción de áridos que ha llegado a hacer desaparecer el arroyo en diversas zonas.

Posteriormente se plantea la recuperación del bosque ripario de una forma lo más natural paisajísticamente, facilitando el acceso y el paseo para descongestionar otras zonas de alto valor ecológico del término municipal.

\section{SUMMARY}

The restoration of the Arroyo (stream) de los Quiñones (San Sebastián de los Reyes) poses a problem whose solution consists in neutralizing the principal sources of its degradation. These sources are: waste water discharges, an urban solid waste dump, situated in the very bed of the stream, and the intensive aggregate extraction which made the stream itself disappear at various points.

This article also deals with the recuperation of the surrounding wood in a natural and lanscape-friendly way, which would facilitate the access and the walk along the sides of the stream. This would lead to the clearing of other areas of a high ecological value within this municipality.

\section{Localización}

La zona a restaurar está situada en el término municipal de San Sebastián de los Reyes, a 20 kilómetros al Norte de Madrid. Comprende el cauce y zonas adyacentes del Arroyo de los Quiñones, en el tramo que va desde la antigua carreterra $\mathrm{N}-\mathrm{I}$, hasta su desembocadura en el río Jarama. La longitud total es de $4.425 \mathrm{~m}$, ocupando un área de $414.369 \mathrm{~m}^{2}$

\section{Objetivos}

En términos generales, con este Proyecto se persigue la recuperación ecológica y paisajística del Arroyo de los Quiñones, para volver a un estado lo más natural posible,

(*) Master en Evaluación y Corrección de Impactos Ambientales. 
y recuperar un espacio altamente degradado, que pueda ser usado por los habitantes de los municipios cercanos como alternativa de esparcimiento y contacto con la naturaleza.

La restauración persigue, además, crear un corredor verde que una zonas actualmente de gran valor ecológico, como son la Dehesa Boyal y el Soto de Viñuelas por un lado, con el río Jarama por otro; intentando descongestionar los primeros de la gran afluencia de público, que los está poniendo en grave peligro.

De forma más concreta se busca:

- La restauración del cauce para que el agua circule libremente.

- La estabilización de las riberas a través del empleo de la vegetación.

- Facilitar el paseo junto al cauce.

- El aislamiento visual de las vistas de baja calidad mediante la plantación de pantallas vegetales.

- La recuperación del bosque de ribera.

- La creación de zonas que faciliten el acercamiento a la naturaleza, descongestionando otras áreas.

- La recuperación de los caminos arbolados.

\section{Estudio del medio físico}

La zona de estudio está encuadrada en un relieve suavemente ondulado con campos de secano. En los primeros tramos, la cuenca visual está limitada por las lomas existentes y la vegetación riparia que enmascaran las vistas de la carretera nacional N-I y de la estación eléctrica al Norte del Arroyo. Aguas abajo la cuenca visual se abre por la ausencia de vegetación y la extensiva extracción de áridos.

El Arroyo de los Quiñones forma parte de la cuenca del Tajo, siendo un afluente del río Jarama. Su caudal es pequeño, con grandes oscilaciones a lo largo del año, llegándose a secar en verano.

Los suelos de la zona han sido utilizados para cultivos de secano, con una productividad baja a muy baja, debido, fundamentalmente, al pobre contenido en materia orgánica y a la textura muy arenosa.

Según los datos climáticos, la zona pertenece a un clima mediterráneo continental templado, con heladas moderadas y donde el déficit hídrico existente es compensado con la humedad proveniente del arroyo, lo que facilitará la revegetación.
La vegetación riparia es una mezcla entre las olmedaschoperas y fresnedas-alisedas mesomediterráneas. En las zonas más alejadas del cauce, la vegetación potencial es la serie de la encina y enebros guadarrámicos. No obstante, debido a la fuerte degradación de la zona, la vegetación existente es escasa y en mal estado de conservación, e inexistente en gran parte del arroyo. Dentro del cauce predominan los zarzales y juncales, como consecuencia de los fuertes aportes contaminantes.

En cuanto a la fauna, es la propia de riberas, aunque condicionada por la escasez de vegetación y la gran cantidad de basuras, que favorecen la proliferación de especies oportunistas y peligrosas para la salud.

\section{Problemática}

El Arroyo de los Quiñones se encuentra en un estado general de grave degradación, estando el bosque ripario prácticamente eliminado; las aguas están altamente contaminadas, lo que sumado a los escasos caudales, acentúa aún más esta situación; el paisaje se encuentra deteriorado por la presencia de la carretera N-I, de una estación eléctrica de la que parten numerosas líneas de alta tensión y de las explotaciones de áridos.

Los factores de degradación más importantes son:

- La contaminación proveniente de las aguas residuales del aliviadero del colector que pasa por la zona (Foto 1).

- Vertidos puntuales de aguas residuales de las fincas vecinas.

- Extracción incontrolada e ilegal de áridos que han modificado el trazado del cauce, llegando a provocar incluso su desaparición en algunas zonas.

- El vertedero de residuos sólidos urbanos existente dentro del cauce (Foto 2).

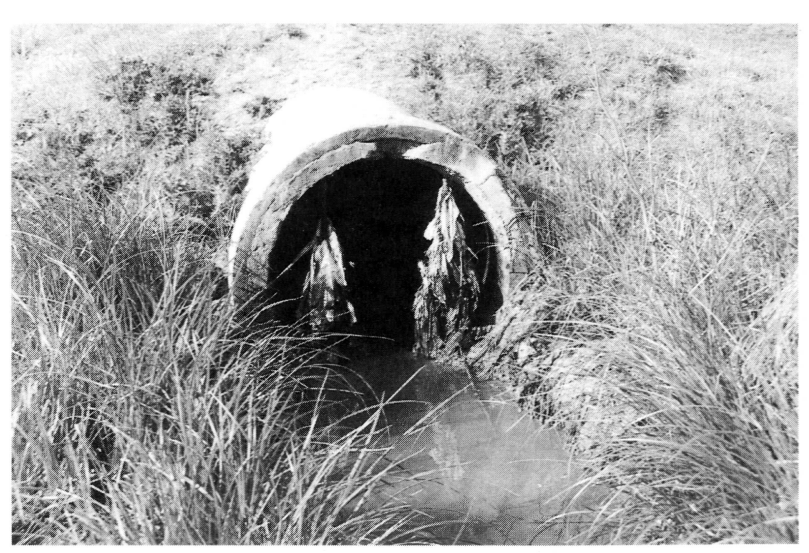

Foto 1.- Aliviadero del colector de aguas residuales. Tramo I. 


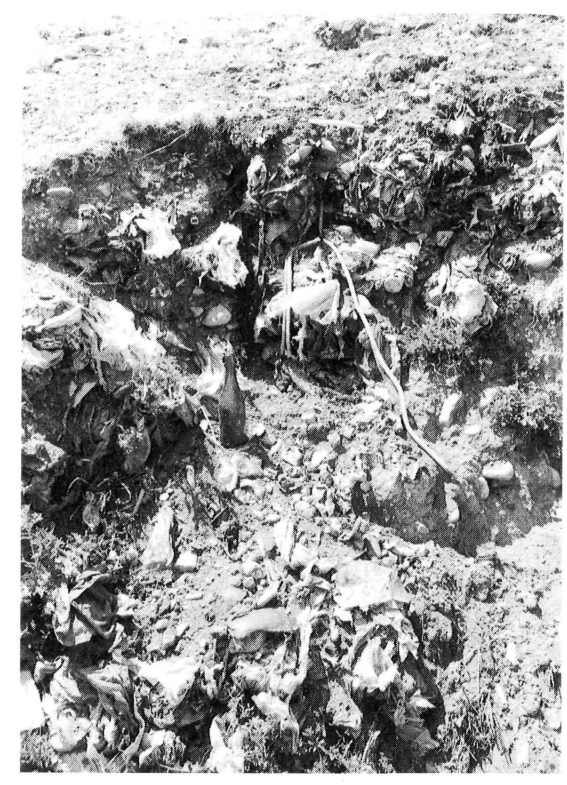

Foto 2.- Vertedero de R.S.U. (Detalle). Tramo V.

Estos factores están influyendo de modo determinante, de tal manera que condicionan absolutamente el éxito del Proyecto. Ninguna actuación debería emprenderse sin antes haber resuelto satisfactoriamente estos cuatro condicionantes. Esto significa la clausura del aliviadero del colector que vierte sobre el arroyo; la solución del problema de las aguas residuales de las fincas colindantes, ya sea mediante su conexión a un colector, previsto en el Plan General de Ordenación Urbana, o mediante la creación, al menos, de fosas sépticas; el sellado del vertedero; $\mathrm{y}$, por último, el cese de la extracción de áridos para permitir una adecuada restauración del arroyo.

\section{Actuaciones}

El propósito principal de las actuaciones es crear un corredor natural desde la Dehesa Boyal y el Soto de Viñuelas hasta el río Jarama para descongestionarlas, ya que actualmente se encuentran muy saturadas de visitantes, al mismo tiempo que se recupera un espacio altamente degradado.

Para lograr esto se seguirán las siguientes líneas de actuación:

-Restitución de trazado original del cauce, perdido en algunas zonas, por la extracción de áridos o por el acúmulo de basuras. La caja del cauce tendrá una forma trapezoidal de $1 \mathrm{~m}$ en la superficie, disminuyendo hacia el fondo hasta una anchura de $0,5 \mathrm{~m}$. Así se le dotará de una caja mínima que permita la circulación del agua y será la propia dinámica del río la que determine las dimensiones y la forma de ésta.

-Limpieza general de basuras, residuos y escombros a lo largo de todo el cauce (Foto 3).

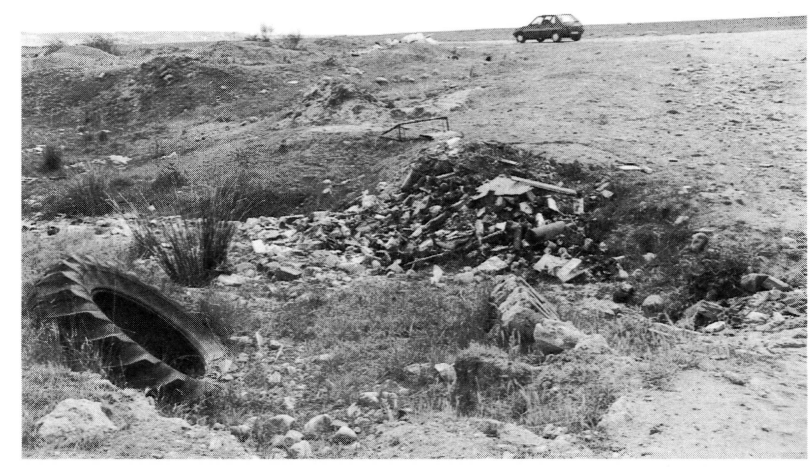

Foto 3.- Basuras en el cauce.

-Eliminación de los focos de contaminación provenientes de aguas residuales que vierten al cauce, mediante su conexión a un colector o la construcción de fosas sépticas.

-Clausura y sellado del vertedero de residuos sólidos urbanos ubicado dentro del cauce del arroyo, que se encuentra al descubierto y en contacto con las aguas superficiales y subterráneas circundantes, constituyendo un gran foco de contaminación. Para la realización de esto se construirá un muro perimetral de hormigón con la profundidad suficiente para crear una sombra a la entrada de agua subterránea procedente de las fincas colindantes al interior del vertedero. En el frente que da al arroyo este muro se rematará en mampostería de un metro de alto para darle más estabilidad al vertedero, protegiéndolo en caso de avenidas. A los residuos se les compactará y se les dará una pendiente mínima (3\%). Posteriormente se colocará una lámina de geotextil y se cubrirá ésta con una capa de arcilla compactada al $95 \%$ para impermeabilizar el vertedero. Por encima se dispondrá $1 \mathrm{~m}$ de tierra compactada y una capa de tierra vegetal que sirva de soporte a la vegetación, en este caso principalmente herbácea y arbustiva. Para evitar la erosión por la escorrentía superficial se construirá un canal perimetral que alejen estas aguas de la zona.

-Restitución del bosque ripario original con especies autóctonas o útiles para la restauración. Además de la vegetación del cauce, se incorporan sectores aledaños del mismo para la creación de zonas de estancia, aumentando el tamaño y la diversidad de la masa forestal.

-Arbolado de los caminos adyacentes al arroyo como pantallas vegetales que disimulen las vistas de baja calidad, y como vías agradables de penetración hacia el arroyo. 


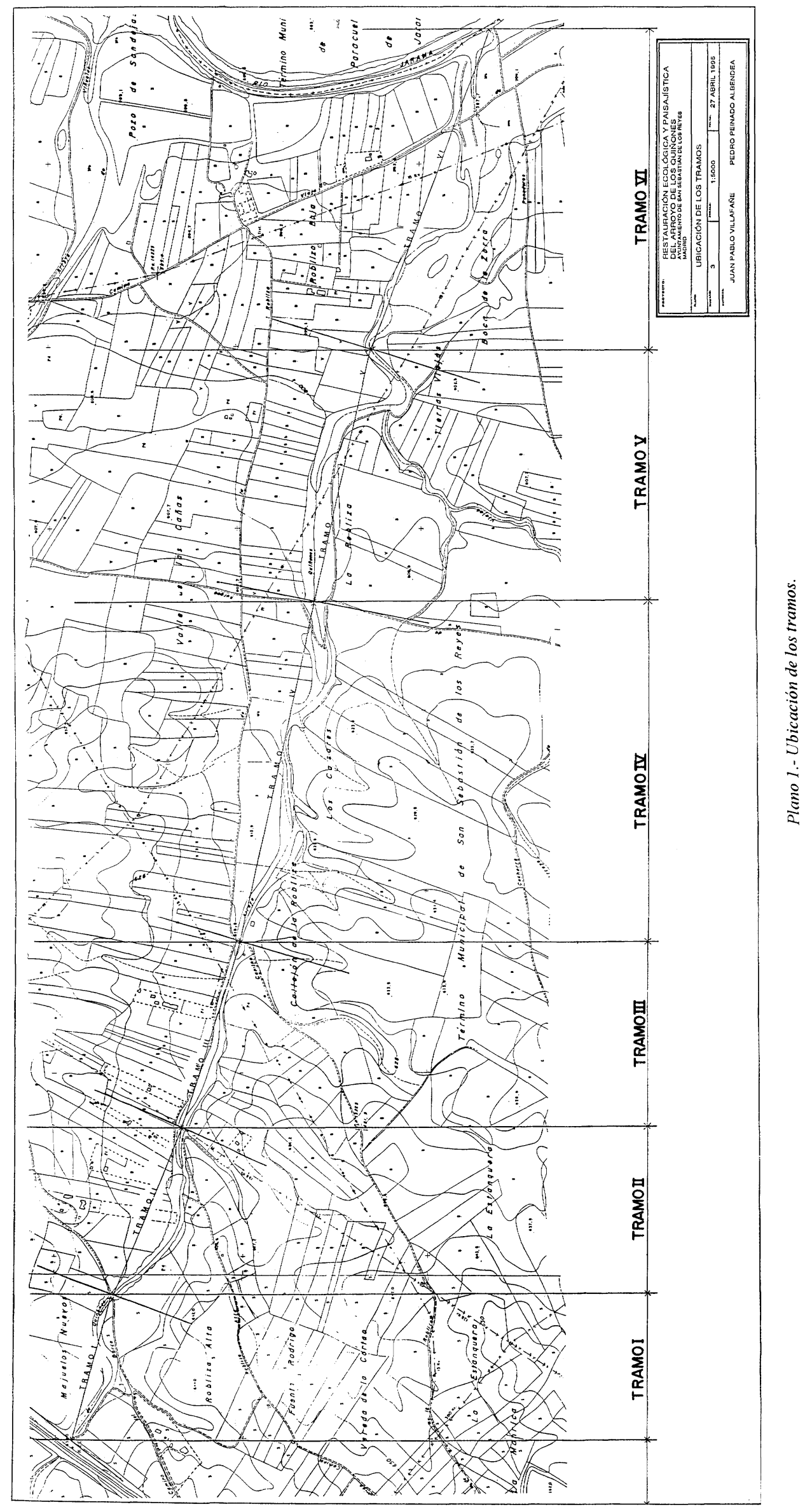


-Creación de aparcamientos al principio y al final del arroyo, zonas de estancia, con algunos bancos como único mobiliario y una senda que los una, recorriendo todo el cauce, para facilitar el acceso y paseo por todo este corredor verde. Estará restringido, a lo largo de todo el arroyo, el acceso de vehículos al cauce mediante la colocación de vallas y pilotes de madera, o de setos de zarzas y majuelos para una mejor integración en el paisaje.

La vegetación a implantar se ha seleccionado teniendo en cuenta la natural y potencial en función de sus requerimientos hídricos. Las especies, sus densidades y tamaños se han variado a lo largo del cauce, para obtener distintas combinaciones de árboles y arbustos, evitando, en todo caso, las alineaciones artificiales, lo que le otorga una mayor naturalidad, diversidad y contraste. Dentro de estas especies, a modo de ejemplo, podemos encontrar chopos, fresnos, sauces arbóreos y arbustivos y alisos principalmente. Estas plantaciones se complementan con un estrato arbustivo compuesto, entre otros, por tarayes, saúcos y majuelos; y con otro hérbáceo que se sembrará donde haga falta, con el fin de evitar la erosión y potenciar la creación de suelo.

Del mismo modo, para las zonas más alejadas, así como también para los alrededores de las zonas de estancia y aparcamientos, se ha seleccionado una vegetación más propia de zonas de cultivos que sirva de nexo entre el bosque ripario y los campos de labor adyacentes. Para estas zonas se han elegido árboles de menor porte pero con mayor colorido y atractivo para los paseantes por sus frutos como son el madroño, el almendro, la higuera, las moreras, el olivo, el tilo, etc.

Para el arbolado de los caminos se ha seleccionado una combinación de árboles de gran porte para crear sombras, que además servirán de pantallas vegetales para las vistas de baja calidad, tan frecuentes en la zona, que es necesario enmascarar, si se quiere que la gente pasee por un paisaje tan desolado, con otras especies que contrastan en tamaño y colorido. Entre estos árboles de gran porte destaca el almez y el pino piñonero. Además se plantará algún ejemplar de encina y quejigo, como ejemplo de lo que en algún tiempo fue el bosque natural de la zona.

El arroyo ha sido dividido en seis tramos para su mejor estudio (Plano 1).

\section{Tramo I}

Éste se inicia en la antigua N-I, que junto con la nueva variante, son un importante factor de degradación visual del mismo. El caudal del arroyo es pequeño, pero se ve incrementado por los aportes del aliviadero del colector de aguas residuales de San Sebastián de los Reyes, con el consiguiente incremento de materia orgánica y contami- nantes, que provocan un crecimiento desmesurado de la vegetación, sobre todo zarzas, del cauce, llegando a cegarlo por completo (Foto 1).

La vegetación arbórea existente es escasa, salvo en la parte final del tramo donde existe un bosquete de chopos en la margen izquierda.

El tramo presenta, además, gran cantidad de basuras y escombros en toda su longitud, debido a su proximidad al casco urbano.

Otro importante factor de degradación es la presencia de un vertedero de áridos, proveniente de la construcción de la nueva N-I. Está compuesto por arenas compactadas que presentan una fuerte pendiente hacia el cauce, lo que unido a la ausencia de vegetación provoca problemas de erosión, acumulándose las arenas en el cauce.

\section{Actuaciones}

En primer lugar, se limpiará toda la zona de las abundantes basuras y escombros, y se desbrozará la vegetación arbustiva del cauce para favorecer la libre circulación del agua. Este desbroce se hará manualmente pues, debido al pequeño tamaño del cauce, si se usara maquinaria se produciría un excesivo deterioro de las márgenes y de la vegetación que los sustenta.

Una acción primordial será la clausura del aliviadero del colector que tan gravemente está contaminando el arroyo.

Igualmente se procederá a la remodelación de los taludes del vertedero de áridos hasta alcanzar una pendiente 1:3, consolidándose ésta con la plantación de herbáceas y arbustos previa aportación de tierra vegetal, debido a la ausencia de suelo.

Las arenas obtenidas con esta remodelación servirán como relleno en los taludes de los últimos tramos.

Finalmente se construirá un pequeño aparcamiento de grava, rodeado de árboles y arbustos para una mejor integración paisajística. De este modo se facilitará el acceso al arroyo, pues de él partirá una senda, de $1 \mathrm{~m}$ de ancho, reservada únicamente a paseantes y ciclistas, que correrá, a lo largo de todo este pasillo verde, saltando de una orilla a otra por pasarelas de madera.

Conectada visualmente con el aparcamiento se habilitará una zona de estancia con bancos, aprovechando un pequeño bosque de chopos, para aquellas personas que no deseen ir más lejos caminando.

Se completará este tramo con las plantaciones del bosque de ribera y de las pantallas visuales para enmascarar la carretera N-I 


\section{Tramo II}

Este tramo preserva gran parte del bosque ripario, aunque no está en un buen estado de conservación. El agua circula libremente hasta casi el final del mismo, donde se encharca por los excesivos vertidos de aguas residuales y basuras que provocan un gran crecimiento de la vegetación.

Por la márgen izquierda transcurre un camino vecinal, frecuentado por coches y maquinaria agrícola, que constituye el principal factor de degradación del tramo, ya que desde el mismo penetran los coches hasta el borde del agua.

A partir del punto en que termina la vegetación arbórea se hace visible la estación eléctrica del Alto de las Ventas, lo que constituye un nuevo factor de degradación visual, que se mantiene hasta el final del arroyo.

\section{Actuaciones}

Las actuaciones deberían empezar con una limpieza general de las basuras y de un desbroce, sólo de los arbustos del cauce. Esto se realizará en todos los tramos siguientes.

Se acondicionará el Camino de Quiñones, paralelo al arroyo, que se encuentra en mal estado por el paso de maquinaria agrícola.

En la zona encharcada, en donde se ha perdido el cauce, se abrirá de nuevo la caja del arroyo, dándole unas dimensiones mínimas para que discurra el agua. Para proteger el cauce del arroyo de la invasión de automóviles se aprovechará un seto natural de zarzas existente entre éste y el
Camino de Quiñones. Solamente habría que podarlo, dejándolo con $1 \mathrm{~m}$ de anchura como máximo. Se abrirían huecos, protegidos con pilotes de madera, para que se pudiera acceder a pie, pero no en vehículo. En las zonas donde falte se instalarán vallas o pilotes de madera, junto con la plantación de arbustos que, con el tiempo, llegarían a enmascarar a aquéllos.

Por último, a lo largo del Camino de Quiñones, en las lindes de los campos de cultivo, se plantará una pantalla de árboles frutales para darles mayor colorido, a la vez que lo integramos mejor en dichos campos. El resto del bosque ripario se plantará atendiendo a los criterios de no seguir un patrón definido y de ensancharlo, en lo posible, a fincas cercanas para evitar que éste sea absolutamente lineal a lo largo del arroyo.

\section{Tramo III}

Éste es un tramo bastante homogéneo. Está cubierto con abundantes basuras, escombros y vertidos. La vegetación principal en el cauce es el zarzal, con algunos sectores de pradera, siendo los.árboles escasos. Por su margen izquierda discurre el Camino de los Quiñones y en la parte final del tramo existe una pequeña laguna antiguamente usada para el riego de las finca vecinas y hoy en estado de abandono con gran acúmulo de basuras (Foto 4).

El agua circula libremente sólo en la segunda mitad del tramo, estando estancada en el resto. La ausencia de árboles permite la visión de la estación eléctrica en toda la longitud del tramo, lo que rebaja la calidad visual de la zona.

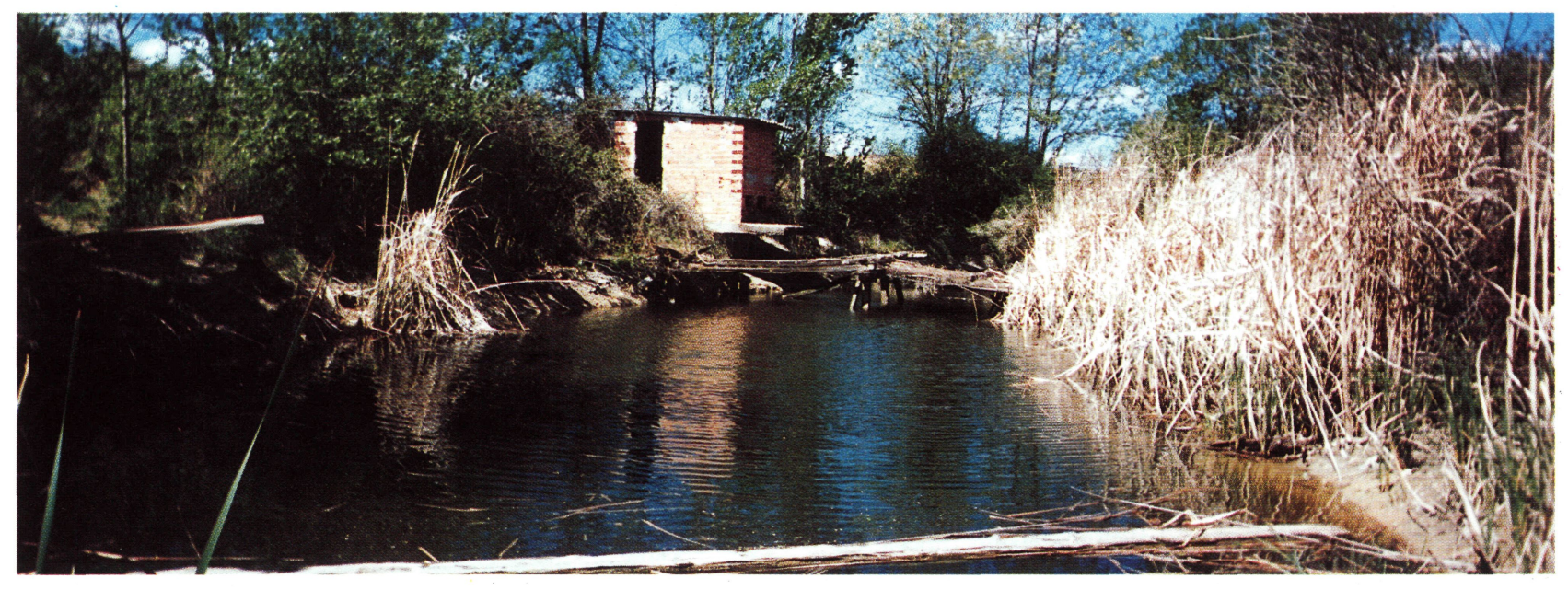




\section{Actuaciones}

Se procederá a la limpieza general de la zona y al desbroce del cauce, principalmente del zarzal.

Se abrirá la caja del arroyo en aquellas zonas donde, por el acúmulo de materiales debido al exceso de crecimiento de la vegetación, sea preciso. Este excesivo crecimiento, sobre todo de juncos, es consecuencia del aporte de materia orgánica proveniente de las aguas residuales de las fincas vecinas.

Para mitigar estos aportes se pueden crear unas "áreas de descontaminación natural". Éstas consisten en unas entradas del arroyo en los márgenes de poca profundidad y sin pendiente, para favorecer el crecimiento del carrizo, que produce una depuración natural de estos vertidos. Estas zonas se crearán en la salida de los colectores de aguas fecales de las viviendas y sus dimensiones variarán en función del terreno disponible en las márgenes en cada caso.

Esto es un remedio paliativo para mejorar la calidad del agua. La solución óptima es la construcción de fosas sépticas o de un colector, ya previsto en el futuro.

El Camino de Quiñones se seguirá acondicionando y se continuará con el seto de zarzas y majuelos para separar éste del cauce. Igualmente, en su borde, se plantará una pantalla de árboles que tape visualmente la estación eléctrica al posible caminante

La laguna será limpiada de todas las basuras y se derruirán las construcciones. Esta limpieza no plantea ninguna dificultaddebido a la poca profundidad existente. El resalte del terreno que le separa del arroyo se dejará con su vegetación actual para que le sirva de protección. El tubo de alimentación de la laguna será desatascado, conectándolo de nuevo al arroyo

La vegetación alrededor de la laguna se aclarará, dejando los árboles del borde exterior y completando la plantación con nuevos ejemplares de chopos y sauces. Así se pretende crear cierta variedad de ambientes a lo largo del arroyo y que sea una zona de estancia más tranquila que el resto de las previstas.

Finalmente se seguirá con la plantación del bosque ripario y la regeneración de la pradera natural mediante laboreo superficial.

\section{Tramo IV}

Este tramo se encuentra bastante bien conservado en su primera mitad a pesar de tener pocos árboles y algunos puntos de vertidos incontrolados (coches abandonados incluidos). Sobre la margen derecha, en un sector sobreelevado, existe una vivienda en ruinas con buenas vistas, que se pretende aprovechar para crear una fresneda como zona de estancia, conectándola con la laguna próxima del anterior tramo.

La segunda mitad del tramo está bastante degradado por la presencia de antiguas extracciones de áridos, que han modificado el relieve y eliminado prácticamente la vegetación. Asimismo, los caminos creados para el acceso a la extracción al pasar sobre el arroyo terminaron por estancarlo, llegando incluso a provocar la desaparición de la caja del cauce por la proliferación de juncos y el depósito de sedimentos.

\section{Actuaciones}

Además de la limpieza general (incluida la retirada de varios vehículos abandonados) y el desbroce de parte de la vegetación arbustiva, se demolerá la vivienda en ruinas, y el puente sobre el arroyo cercano a ésta, construyéndose uno nuevo, lo más integrado posible en el paisaje.

Se abrirá la caja del arroyo en la zona que está estancada para facilitar el flujo de la corriente.

Debido a la extracción de áridos algunas zonas presentan un relieve muy irregular. Se remodelará el terreno hasta conseguir unas formas más naturales, regenerándose la pradera natural mediante un laboreo, abonado y siembra, debido a la pobreza del suelo en estas zonas.

Se completarán las actuaciones en este tramo con la plantación del bosque de ribera, el arbolado de los caminos próximo,; la creación de dos zonas de estancia con algunos bancos, una de ellas sólo con fresnos, y la otra con más variedad de especies, incluyendo árboles frutales para crear más diversidad y, por último, la senda que, proviniendo del tramo anterior, atravesará estas zonas y llegará hasta el final del arroyo.

\section{Tramo V}

Este tramo es uno de los más degradados del arroyo debido, principalmente, a la extracción de áridos al que fue sometido. El relieve y el trazado se encuentran totalmente modificados, rellenándose posteriormente el hueco dejado por la explotación con residuos sólidos úrbanos, además de otros, tóxicos y peligrosos (Foto 5).

Esto ha generado en el mismo cauce un vertedero incontrolado de gran potencia, con los residuos al descubierto en la actualidad, y en intimo contacto con el agua superficial y subterránea, lo que aporta una carga extra de contaminantes con el consiguiente peligro para el acuífero. 


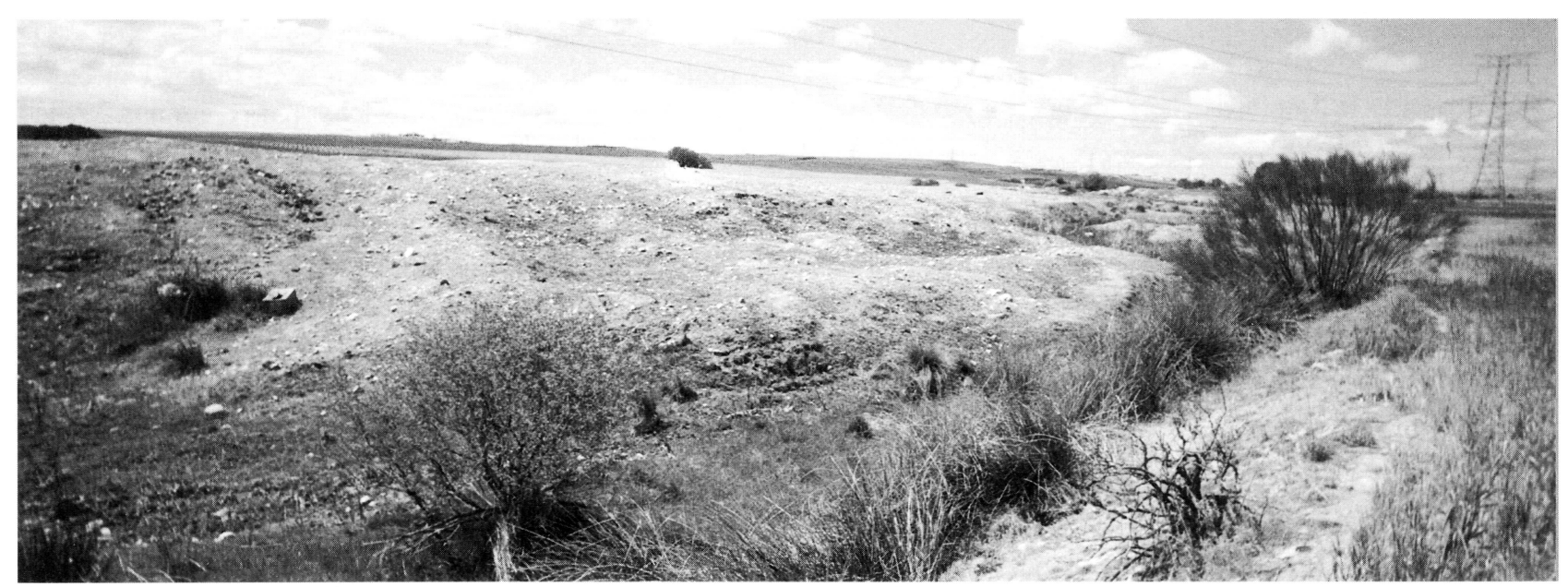

Foto 5.- Vertedero de residuos sólidos urbanos. Tramo V.

El agua circula sólo en la segunda mitad del tramo, estancándose ocasionalmente. Existen además algunas lagunas, de carácter freático, debido a la profundidad a la que se produjo la extracción de áridos.

La vegetación arbórea es inexistente, quedando reducida sólo a vegetación herbácea y juncales.

\section{Actuaciones}

En este tramo lo más importante es el sellado correcto del vertedero existente en el cauce. Después de una limpieza general de la zona, que está profusamente salpicada de todo tipo de basuras, se procederá a la construcción del muro de hormigón perimetral al vertedero que evitará que las aguas de escorrentía penetren en el mismo. Después de compactar los residuos se dispondrá una lámina de geotextil, una capa de arcilla compactada, una capa de $1 \mathrm{~m}$ de tierra para el soporte de la vegetación y una capa de tierra vegetal de $5 \mathrm{~cm}$ antes de plantar los arbustos y herbáceas que lo protegerán. No se plantarán casi árboles, ya que éstos necesitan al menos $2 \mathrm{~m}$ de tierra soporte, no siendo viable en esta ocasión, ya que resultaría un relieve muy por encima de las fincas colindantes, lo que paisajísticamente no sería adecuado en una zona bastante plana (Plano 2).

Toda la zona que conserva el relieve removido de la extracción de áridos se remodelará para alcanzar unas formas más naturales, incluyendo la restitución del trazado original del cauce allí donde se haya perdido o modificado. En estas zonas se necesitará aportar tierra vegetal antes de sembrar el pastizal debido a la pobreza del terreno.

Se mantendrán las dos pequeñas lagunas freáticas para crear una mayor variedad de ambientes y que puedan, en su caso, servir para las aves acuáticas observadas en la zona. Sólo necesitarán una limpieza y una plantación, en este caso de sauces, alrededor, que las separe de alguna forma del resto del cauce.

Por último, se plantará el bosque de ribera que, como viene siendo habitual, se compone de distintas combinaciones de sauces, alisos, chopos, fresnos, tarayes, saúcos, etc. En las partes más alejadas y elevadas respecto al cauce se plantarán otro tipo de árboles más relacionados con los cultivos cercanos como son olivos, higueras, almendros, madroños, etc. (Plano 3).

\section{Tramo VI}

En su totalidad este tramo ha perdido su fisionomía original por la intensiva extracción de áridos, quedando como una zona totalmente excavada, con huecos, montículos de arena, etc. (Foto 6).

Los taludes de la margen izquierda presentan unas pendientes excesivas que, sumado a su gran altura, plantea problemas de estabilidad.

La vegetación está prácticamente ausente, y el cauce aparece sólo en la primera mitad del tramo para luego infiltrarse el agua entre los materiales de la explotación, apareciendo ésta en las proximidades de río Jarama, junto con las aguas del lavado de los materiales, cargados por ello con sedimentos. Lo que agrega una nueva carga contaminante al río Jarama.

Actualmente se está explotando esta gravera de forma ilegal e incontrolada, previéndose su clausura próximamente. 
111

Informes de la Construcción, Vol. 47 n ${ }^{\text {s }} 441-442$, enero/febrero - marzo/abril 1996

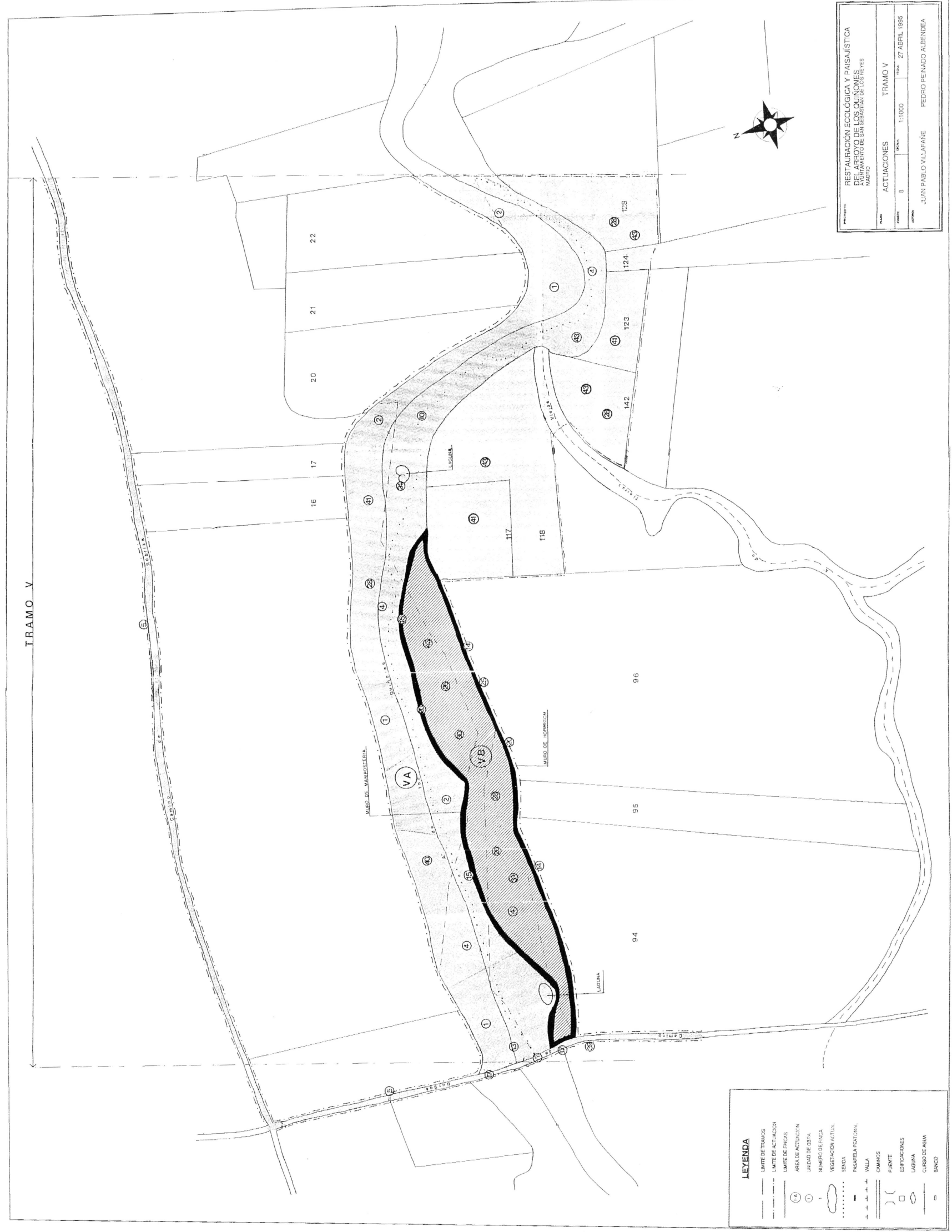

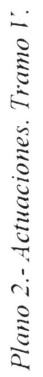

(c) Consejo Superior de Investigaciones Científicas

Licencia Creative Commons 3.0 España (by-nc)

http://informesdelaconstruccion.revistas.csic.es 


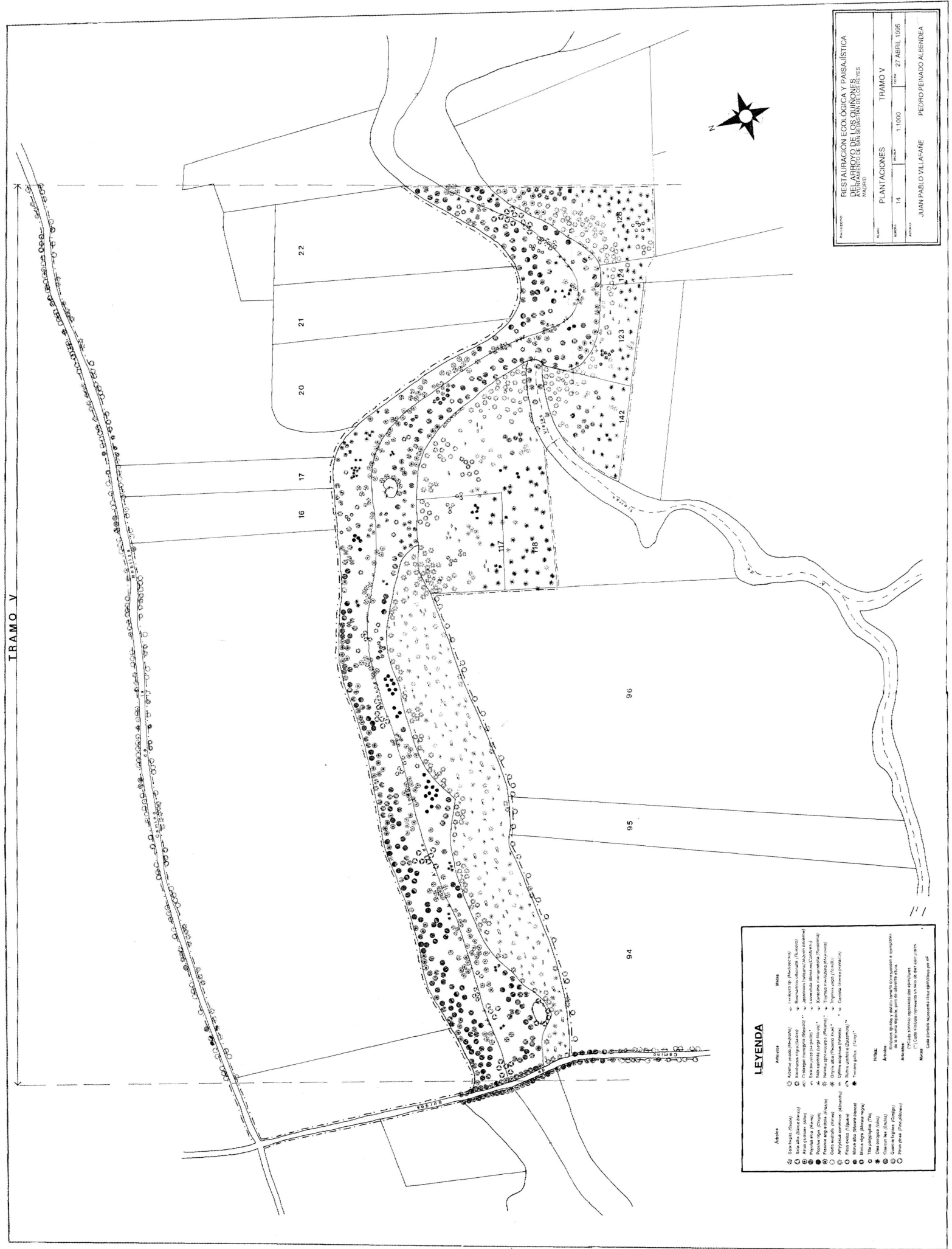




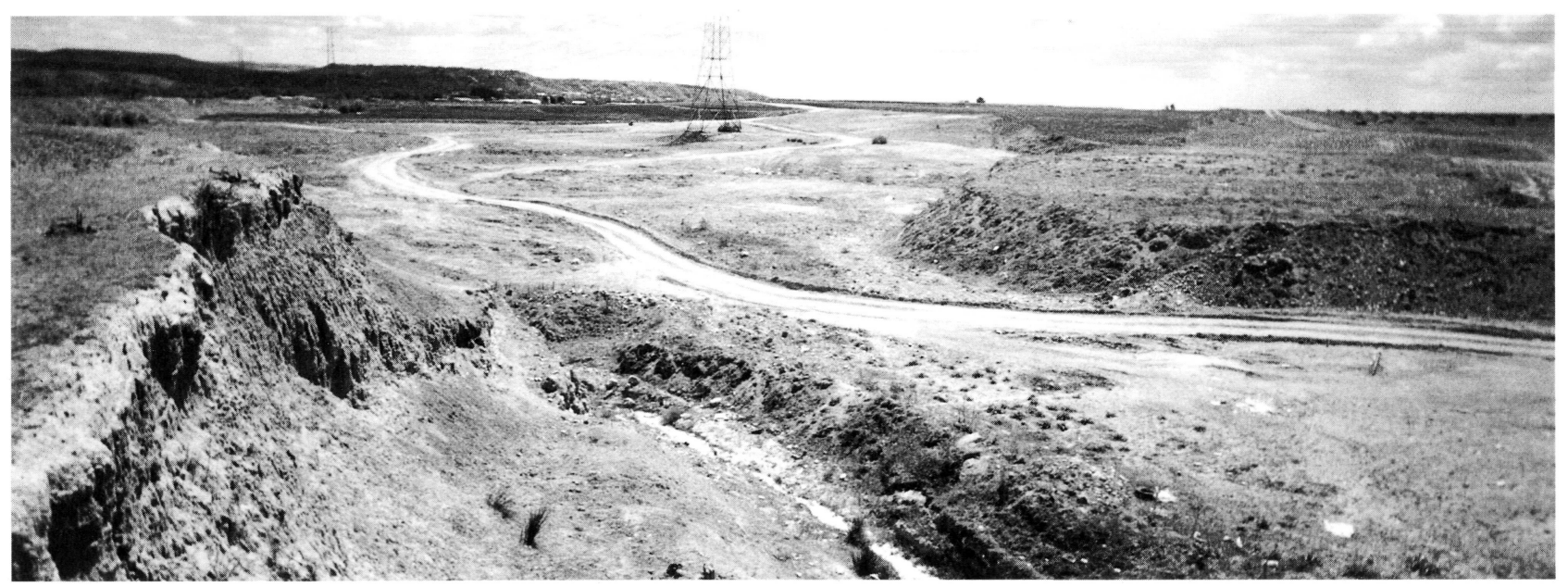

Foto 6.- Vista general. Tramo VI.

\section{Actuaciones}

Lo primero a abordar en esta zona del arroyo es la remodelación profunda de los terrenos hasta alcanzar unos perfiles suaves, más naturales, con una ligera pendiente hacia el cauce del arroyo.

Del mismo modo se remodelarán los taludes con problemas de erosión. Para rebajar su pendiente hasta conseguir unas cercanas a 1:3, se aportará material en su base, para evitar comer terreno a las fíncas de la cabecera del talud. Parte del material de relleno proviene de las otras remodelaciones de otros tramos del arroyo. Para evitar la erosión se sembrará con pastizal y se plantarán arbustos, pudiendo en la base plantar una arboleda más densa para defenderlo.

Debido a que ha desaparecido la caja del arroyo se procederá a su apertura de nuevo, manteniendo el trazado que existía antes de la explotación de la gravera.
Dada la inexistencia de suelo se descompactará mediante laboreo todo el terreno del cauce y se recubrirá con una capa de $5 \mathrm{~cm}$ de tierra vegetal para la siembra de la pradera y la plantación del bosque. En el centro del cauce, proximo al curso de agua, se recupera el bosque ripario con las especies habituales, hasta el final del arroyo. En el borde externo se repoblará esta última zona con una variedad de especies, siendo la principal el pino piñonero.

Para finalizar, se acondicionará y arbolarán los caminos cercanos al cauce, deteriorados por el paso de maquinaria pesada, que terminarán en un pequeño aparcamiento, contiguo a la última zona de estancia, donde terminará la senda peatonal que recorre, de principio a fin, el arrroyo.

Con esta última zona de estancia y el aparcamiento se pretende una mejor distribución de los futuros usuarios de este paseo natural, al facilitar su acceso con vehículo por diversos lugares, evitando así que la gente se concentre en el primer tramo. 